\title{
Virtue, In Context
}

\author{
DANIEL H. COHEN
}

Department of Philosophy

Colby College

Waterville, ME 04901

USA

dhcohen@colby.edu

\begin{abstract}
Virtue argumentation theory provides the best framework for accommodating the notion of an argument that is "fully satisfying" in a robust and integrated sense. The process of explicating the notion of fully satisfying arguments requires expanding the concept of arguers to include all of an argument's participants, including judges, juries, and interested spectators. And that, in turn, requires expanding the concept of an argument itself to include its entire context.
\end{abstract}

Résumé: La théorie des vertus d'argumentation fournit le meilleur cadre pour accueillir la notion d'un argument qui est «entièrement satisfaisant» dans un sens solide et intégré. Le processus de l'explication de la notion d'arguments pleinement satisfaisants nécessite l'élargissement du concept des raisonneurs de façon à inclure tous les participants à l'argument, y compris les juges, les jurés et les spectateurs intéressés. Et ceci, à son tour, nécessite l'élargissement du concept d'un argument lui-même à l'ensemble de son contexte.

Keywords: arguer, argumentation, virtue

\section{Introduction: The virtues of OSSA}

I would be remiss if I did not begin by expressing my deep gratitude to the Ontario Society for the Study of Argumentation conference organizers for the opportunity to be one of this year's keynote speakers. It is a privilege and honor, but the responsibility has caused me no end of sleeplessness for many months now. More than that, however, I would like to thank Tony Blair, Ralph Johnson, Hans Hansen, Chris Tindale, and now Cate Hundleby, for the dedication and energy they have invested in establishing and sustaining this conference over the years, and for their important, intelligent, and graceful contributions to the field of argumentation theory.

I have grown especially fond of the OSSA conference because not only has it been an exemplary forum for thinking and learning and, of course, arguing, about good argumentation, but it has also been a showcase for good argumentation. The system of commentators, together with the opportunity for 
replies in the Proceedings, and the culture of collegiality all bring out the best in us as arguers. It has fostered the exchange of ideas and provided the chance to argue, reflect and revise, all within an open and supportive environment. To put it in more timely words, this conference brings out the virtues of argumentation and puts them on display.

Not surprisingly, then, OSSA has been an occasion for some very good arguments-some very, very good arguments. On at least a couple of occasions, arguments so good that they left me almost speechless - so satisfied that there was nothing left to say.

Think about that for a moment: an argument that can leave a philosopher speechless? Now that's a good argument. ${ }^{1}$

We could take that as a starting point - the idea of an argument so good that it completely satisfies its participantsbut let us be less presumptuous and take it as a starting goal.

Instead, let me start with the conference theme: the Virtues of Argumentation. It is a phrase rich with meanings, reflecting some of the different ways we can think about arguments. Two readings in particular stand out: First, it can be read as referring to the various positives attributes that argumentation has as a means of settling disputes, as a method for arriving at truths, or for any of the many other ways in which argumentation is a good thing. Alternatively, it can be interpreted as referring to the virtues exhibited by arguers in arguments, rather than by argumentation. What positive attributes are exhibited by arguers when those arguers are arguing well?

Is there anything more than an accidental, homonymic connection between these two ways of reading the phrase, "the virtues of argumentation"? The question of how good arguing is conducive to what arguing is good for cannot be ignored when trying to answer the question of how good arguing could lead to arguments that are good- especially when the goal is arguments that are that good. The larger question of the nature of argumentation informs all subsidiary discussions, so if we focus too narrowly on either good arguments or good arguing, we run the risk of missing something important.

So, what I would like to do is connect virtuous arguing with satisfying arguments and the value of argumentation. There are, then, three bearers of value to ask about:

- What makes an arguer praiseworthy;

-What makes an argument praiseworthy;

- What makes argumentation praiseworthy.

${ }^{1}$ This notion of argument was introduced in Cohen 2008.

(C) Daniel H. Cohen. Informal Logic, Vol. 33, No. 4 (2013), pp. 471-485. 
Now that's what I would like to do, but unfortunately, I lack the talents to succeed at such an ambitious project. Mercifully, I lack the hubris to even try, so, instead, I will focus more narrowly on the virtues of virtue as a tool for theorizing. Virtues, I shall argue, provide a particularly good lens for thinking about our questions, but ultimately there are limits to their theoretical utility. They cannot underwrite a complete account.

\section{Whence virtues?}

The history of my thoughts about virtue and argument runs right through OSSA, so if you will indulge me just a little longer, I'd like to rehearse some of that history because I think it helps to explain how we can get from thinking about arguments to thinking about virtues, why the field of argumentation and virtues is so fertile, but also why in the end we will need to move beyond traditional thinking about virtues.

The first mention that I heard of "Virtue Argumentation" came in 2006. I had presented a paper at the 2005 OSSA meetings about a peculiar class of especially bad arguments that I labelled "Backfiring Arguments" because the effect they end up having is to lower rather than enhance the credibility of their target conclusions. It takes a heroically bad arguer to pull that off, and I explored some of the features of arguers that could lead to contribute to that sort of misfire. The principal virtue of that paper was that it managed to elicit a very good response from Andrew Aberdein, the OSSA-assigned commentator. Aberdein built upon that commentary in the paper, entitled, "Virtue Argumentation,", that he presented the next year at the International Society for the Study of Argumentation conference in Amsterdam. In that presentation, he referred to my paper and to me as, and I quote, "a virtue argumentation theorist avant la lettre." He then announced that he was in fact publicly "outing me" as a Virtue Argumentation Theorist.

Prior to that, I had not thought about the connection between Virtue Epistemology and Argumentation Theory, so for that piece of generous "hermeneutical ventriloquism" I am very grateful. The juxtaposition of those ideas helped crystallize my thoughts and bring into focus two distinct but convergent pathways from virtues to arguments.

${ }^{2}$ The paper was later published as Aberdein 2010.

(C) Daniel H. Cohen. Informal Logic, Vol. 33, No. 4 (2013), pp. 471-485. 


\section{A traditional story}

The first, shorter path linking virtues and arguments is best told in a story. It's an old story, one that some of you have undoubtedly heard before, quite possibly from me because it is one that I rather enjoy telling. I think it bears repeating:

Many years ago, at one of the large synagogues in New York serving a congregation of immigrants from around the world, there was a heated dispute that threatened to tear the congregation apart. Should the canonical prayer, Shema Y'Isroel, be recited seated or standing? Rather than let the argument destroy the congregation, they all agreed to defer to the Rabbi who would be hired when their current one, who was already quite old, retired. The time came and they conducted an exhaustive international search, settling on a Rabbi with an impeccable reputation as a brilliant scholar. When he arrived at the temple, he was immediately surrounded by elders from the congregation.

"Rabbi, Rabbi," one elder asked, "Isn't it traditional for the Shema to be said while seated?"

The Rabbi paused, stroked his beard, and then said, "No, that is not the tradition."

"Aha!" another elder exclaimed. "So we were right! The tradition is to stand when reciting the Shema, isn't that so, Rabbi?"

"No, that is not the tradition either," came the reply.

"But, Rabbi," said another, "we've been arguing about it for years!"

"That's the tradition!"

If you are like me and find nothing especially conceptually odd about the idea of recreational argument, then perhaps you'll also find nothing odd about a tradition of arguing either, but there is indeed something peculiar about it. It's not just that some of the details of the Talmudic tradition of pilpul argumentation are so interestingly idiosyncratic. The same can be said about the Buddhist Gelukpa tradition of argumentation (rtsod pa) or any other argument-centered tradition. The oddity is in the very idea of a tradition of argument. Isn't arguing about differences, while traditions are about community? Yes, and it is true that one of the things that arguments can do is resolve differences, but in order for arguing to be a positive constituent of a tradition, arguing cannot be understood simply as a way of

(C) Daniel H. Cohen. Informal Logic, Vol. 33, No. 4 (2013), pp. 471-485. 
eliminating (negative) differences. Nor can it be thought of as a means to truth and knowledge or even as a manifestation of an individual's rationality. Arguing would have to be a way of participating in the community. If arguing is to be part of a tradition, it cannot be about who I am or what I do; it's about who we are and what we do. We argue with one another, not in isolation.

It is the doing, not the deed, that matters, and the doing is a communal effort.

Admittedly, when I say this, I have tipped my hand. I am not thinking of arguments as abstract structures of inferentially connected propositions. Otherwise, simply presenting valid arguments would make one part of the tradition, but that is not so. It's not enough to walk around saying, "Socrates is Greek; All Greeks are mortal; Therefore Socrates is mortal." That isn't arguing: it isn't honoring a tradition; it's being eccentric.

Obviously, something more is needed to make logical inferences into dynamic, vital arguments capable of centering a tradition. And that something more is arguing with others. But even that is not enough, otherwise being excessively argumentative would make one a pillar of the community! What's needed is not just arguing with others, but doing it well, that is, virtuously.

\section{Up and down approaches to argument}

The path that I in fact followed from arguments to virtues was more of a long and winding road, with a detour through what probably deserves to be called a "weird methodology."

The methodological challenge for argumentation theorists is that argumentation is manifestly not a single phenomenon, nor even a single multi-faceted phenomenon. It is a heterogeneous set of many different phenomena, many of which are themselves multi-faceted. The great diversity of facets and phenomena requires a plurality of paths into the discussion, and as a community we have responded in kind. Logic, rhetoric, and dialectic may be the most prominent approaches we have developed, but there are others. There are linguistic and sociological dimensions to argumentation; the anthropology of argumentation is no less a part of a complete account of argumentation than its psychology; and even if we accept the assumption that epistemology provides the ultimate telos of argumentation, that does not license us to ignore the ethics of argumentation or its juridical and political aspects. 
We can draw a rough-and-ready distinction between two general classes of strategies for approaching arguments, "topdown" and "bottoms-up." Top-down theorists begin with an idea of what an argument is or ought to be. That conception can then serve up criteria for what makes a given argument praiseworthy. Normative principles for good argumentation can be extracted by a straightforward conceptual analysis and then deployed in particular cases. In practice, the initial conceptualization does not have to be held as fully sacrosanct, and the give-and-take between the initial assumptions and the results from application will sharpen or otherwise enhance the initial concepts. There is room for the dynamics that lead to reflective equilibrium and a stable theory that is yet capable of further evolution.

The proof of the work of top-down theorists can be found in the templates they have provided and the principles that have emerged. A lot of first-rate theorizing falls under this rubric and there is no denying the extraordinary magnitude and extent of the successes that have been achieved this way.

We have also been the beneficiaries of very impressive contributions by those working from the other end of the spectrum. The technology is in place for dedicated researchers to make a thorough corpus analysis or to conduct extensive empirical studies, and we are fortunate to have such careful scholars among us whose hard work and systematic data collection transcend the inherent biases of anecdotal data selection.

The proof of the work of bottoms-up theorists can also be found in the principles that have emerged and the templates they have provided. A lot of first-rate theorizing falls under this rubric and there is no denying the extraordinary magnitude and extent of the successes that have been achieved this way.

\section{The weird road to virtues}

Lacking the rigor and analytical insights of Top-down theorists as well as the perseverance and synthesizing abilities needed for empirical Bottoms-up research, I have had to cobble together a mixed approach. Beginning at one end, I have focused on what I suppose are "weird" arguments in the hopes that something about the entire class can be discerned from exploring the outliers, oddities, extreme cases, and pathological deformities that mark the boundaries. I have mentioned one class already, Backfiring Arguments, but I have also been intrigued by such curious examples as: 
- Arguing with God where you know you can't win;

- Arguing with Oneself where you really can't lose;

- Walkover Arguments where you win too easily, but there might not be anything to win;

- Academic Arguments where it seems no one ever really wins, but there's really not much at stake to win or lose, anyway;

- Filibusters where one party refuses to play at all—and makes sure that no one else gets to play either;

- Desperation Arguments where normal strategies can be thrown out the window because you've almost certainly lost already so there's nothing left to lose;

- Misbegotten Arguments where there's an argument, but there shouldn't be one, so simply choosing to argue is already an argumentative failure;

- Impossible Arguments that cannot be won by argumentation and can only be resolved by something other than argument, e.g., by a wholesale, radical epistemic conversion rather than a more localized standpoint adjustment — but have to be argued regardless;

- Missing Arguments where there's no argument, but there should be one, so in this case it is the decision NOT to argue that is the argumentative failure;

- Misfit Arguments by the wrong people in the wrong place at the wrong time about the wrong thing, i.e., arguments that are Misplaced, Displaced, and Out-of-place.

I find all of these cases individually fascinating, and collectively helpful when thinking about all the different aspects of arguments and all the ways that things can wrong in an argument. In each case, something is deficient or completely missing that should be there or else something is exaggerated or present that shouldn't be there at all. These arguments are unsatisfying, regardless of whether they merit any of the honorifics we normally bestow on arguments, like valid or sound or cogent or kosher.

The job then becomes one of trying to locate the intruding or missing pieces that make the argument less than fully satisfying. That is, these examples lead us to ask: What virtue is missing? And What vice is present?

And that returns us to the earlier question as to what it would be for an argument to be fully satisfying. What would make an argument satisfying to the point that the participants could say at the end, "Now that was a good argument"? An awful lot of pieces have to fall into place for an argument to be that good.

(C) Daniel H. Cohen. Informal Logic, Vol. 33, No. 4 (2013), pp. 471-485. 


\section{6. "Now that was a good argument"}

The most obvious - and most important - thing to say about an argument that is so good that in the end the arguers agree on how good the argument was, is that it must have some extraordinary arguers! It is an exceptional arguer who can see the epistemic gains to be had, and thus be satisfied by, losing an argument, and it is equally admirable for a winning arguers to appreciate the contributions made by her opponent to whatever epistemic gains she has made.

The notion of an argument that is fully satisfying to its participants includes more than epistemic gains. It has to at least extend to cognitive gains more broadly, including emotional, ethical, and possibly aesthetic aspects as well. It is a conceptually rich deposit for theorists to mine. In order to excavate that wealth we need to decide what counts as an argument, who counts as a participant, and, most of all, what counts as satisfying. I will begin with and focus on the last one because it informs and integrates the other two.

We can take a cue for the idea of a fully satisfying argument from The GoodWork project of psychologists Mihaly Csikszentmihalyi, William Damon, and Howard Gardner. ${ }^{3}$ They note that when we speak of "good work" we may have technical competence in mind: we hire master craftsmen precisely because they can be expected to do good work. We might instead be commenting on whether it is engaging, rewarding, or satisfying for the workers: we all want good jobs-good workin that sense. And we could also be judging that the work is ethical: people who volunteer their time in soup kitchens or hospitals are doing good work. It is easy enough to separate the different senses - as I have just done - but I think some damage is done both conceptually and practically if we accept that fragmentation without any resistance. Our lives and works should be more integrated than that.

The same thing needs to be said about good arguments. There is, of course, great clarity to be gained by analytically distinguishing such elements as the technical competence in arguments from the cognitive gains to be brought about by arguing or the ideal conduct of arguers during arguments or the satisfactoriness of its resolution. But there is also the potential cost of losing the forest for those trees.

Suppose, for example, that we focus exclusively on technical competence, something like inferential validity. It becomes all-too-easy to lose sight of the dialectical, rhetorical,

3 The GoodWork Project: http://www.thegoodproject.org/good-work/

(C) Daniel H. Cohen. Informal Logic, Vol. 33, No. 4 (2013), pp. 471-485. 
and other dimensions of argumentation. Here's an example of an argument offered by a leading logic text: "Both Pierre and Marie Curie were physicists. Therefore, Marie Curie was a physicist."

\section{Really? That's your example of a good argument?!}

I suppose it could serve as an example of a good inference, but as an argument, it leaves so much to be desired that one wonders how it could even be offered as an example of an argument in the first place. Only someone with logical blinders on-like the author of an introductory logic text-would consider it. I cannot imagine someone walking away from an exchange that include the words, "Both Pierre and Marie Curie were physicists. Therefore, Marie Curie was a physicist," saying to herself, "Wow, that was one heck of a good argument!"

The relevant concept of an argument that is implicated by the robust concept of a fully satisfying argument, therefore, cannot be the logical notion of a valid inference. Good inferences do not by themselves make good arguments.

As an aside, and more controversially, I also think that bad inferences do not necessarily ruin an argument. First, it would have to be recognizably bad inferences, rather than merely invalid ones, that would disqualify an argument. But even that might not be enough.

Under certain circumstances, it is not necessarily unreasonable to overlook an argument's flaws. One might, for example, resort to a meta-argument like this: "I can see that the argument doesn't work as it stands, but the conclusion is so attractive that I'm sure someone will be able to fix it. I'll accept this flawed one for now." The French mathematician and physicist Henri Poincaré suggested that he sometimes operated this way: accepting a formula as a provisional lemma in proving theorems before he had any proof for that lemma.

There is a negative counterpart to the reasoning here that is actually fairly common: a meta-argument for rejecting apparently good arguments, the "MARGA gambit." We find it on display whenever someone rejects a supposed sophistry without being able to identify the specific problem: "I can't find anything wrong with this proof that $1=0$, but I know that can't be right, so I'm confident that a competent mathematician could find the error, so I'll reject it even though it looks perfectly good to me."

Valid reasoning is apparently neither necessary nor sufficient for an acceptable argument. Still, the degree of

${ }^{4}$ The author's name is withheld out of respect.

(C) Daniel H. Cohen. Informal Logic, Vol. 33, No. 4 (2013), pp. 471-485. 
acceptability is limited. Provisionally accepting an unproved lemma falls well short of "fully satisfying." Fully satisfying is a very high standard.

Similar examples can be found or generated to show that exclusively rhetorical, dialectical, epistemological, or ethical criteria for good argumentation also fail to capture the robust concept. Winning arguments, for example, do not necessarily qualify as good arguments in this rich sense: If the loser of an agonistic does not walk away satisfied - and how often does that happen? - then there is some dissatisfaction, so it is not fully satisfying. For that matter, how often is the nominal winner of an argument satisfied? If there is nothing to gain from a "walkover argument" against an overmatched or incompetent opponent, at least from an epistemic perspective, then whatever satisfaction is to be had is limited. Even rationally persuasive arguments can leave a bad taste in one's mouth. Again, this is a very high standard.

Virtuous argumentation does fare better on this count if only because the arguers will have the appreciable satisfaction of having argued well. But even then, I shall argue, something is still be missing.

To be fair, argumentation theorists have generally avoided these sorts of one-dimensional characterizations of what makes a good argument, so admittedly I am taking shots at an army of Straw Men here. But I can always use the reminder to widen my perspective. The concept of a good argument is a complex, multi-faceted one. In the jargon of contemporary philosophy, it is a "thick" concept: it encompasses both strictly descriptive components and loaded normative ones.

\section{The cast of arguers}

If we are going to invoke the idea of an argument that is fully satisfying, we cannot then turn around and think of arguments as abstract structures of propositions. For starters, there have be arguers to $b e$ (or fail to be) satisfied. And we need to expand the category of "arguer" to include everyone who is relevant for the judgment that an argument is, or is not, fully satisfying. Two criteria for relevance present themselves:

(1) anyone who has the standing to evaluate the argument itself as being satisfactory or not

(2) anyone whose conduct is properly subject to being evaluated as satisfactory or not 
By and large, these criteria identify many of the same people. The proponents of a standpoint and their opponents are included by these criteria, and so are any third-party interlocutors. In addition, these criteria also include judges, juries, and interested spectators. In some contexts, it would make sense to extend the list even further so as to include any party with an interest in the outcome, but it might be best not to open that can or worms now-if only because when the argument concerns environmental issues, actual worms could qualify as interested parties and therefore participants in the argument. Let it suffice for the moment simply to emphasize that when it comes to including different perspective in the overall evaluation of an argument, the wider the net, the better.

In another context, I labelled some of these other parties "non-combatants" to distinguish them from the primary protagonists (Cohen, forthcoming). Part of the reason for that terminology was to exploit the dominant argument-is-war metaphor, and to show that despite its significant defects - and the significant pleasure that many of us have had in pointing out those defects - there is still new and useful meaning to be extracted from the argument-is-war metaphor. The idea of noncombatants implicates the related concept of "collateral damage" - and that is an idea that can fruitfully be transplanted from the military sphere to the discourse of argumentation. Here, however, I will label them "supporting actors" in order to highlight their secondary roles as well as their secondary contributions to the overall performance.

Each of the two criteria just noted provides a compelling reason to count these supporting actors alongside proponents and their opponents as part of the cast of characters in an argument. First, they have a stake in the argument. Thus, they have the standing to make a judgment as to the satisfactoriness of the argument. They may not have as much to say about the argument as the proponents and opponents but that does not mean that they don't have anything to say. Consider a legal case: If the judge and jury are not satisfied with the argumentation, that tells us something; if the defendants or plaintiffs have complaints about their counsels' argumentation, that matters, too; and if the spectators find it lacking, that also counts.

Second, in addition to having a stake in the argument, the supporting actors add something of their own to the argument. And it cuts both ways. Knowledgeable audiences, fair-minded judges, and conscientious juries can be significant, positive factors in the success of an argument. Conversely, incoherent proponents and intransigent opponents are not the only ones

(C) Daniel H. Cohen. Informal Logic, Vol. 33, No. 4 (2013), pp. 471-485. 
who can spoil an argument; biased arbitrators, incompetent juries, and uninformed, unappreciative, or ill-behaved audiences have that power, too.

\section{Different strokes for different folks}

In addition to the two antecedent reasons for counting supporting actors as arguers, namely their stakes in the outcome and their contributing roles in producing that outcome, there is an another benefit to thinking along these lines that gives a degree of posterior confirmation to that decision. It casts a bright light that clarifies the role of the virtues in argumentation and thereby brings the concept of an arguer's virtues into clearer focus. In so doing, it highlights the strengths of virtue an analytical tool.

At the same time, however, it also reveals limits to what virtue argumentation theory can do.

First, the positive part: the core ideas of Virtue Argumentation Theory, as I understand it, can fit on a couple of bumper stickers. First,

For a good argument, argue well.

The grammatical shift from the adjective "good" to the adverb "well" signals a change in focus from the argument as a product to the arguer as an agent. Virtue Argumentation Theory zeroes in on the conduct of the arguers, rather than on propositions, rules, inferences, procedures, or even outcomes, as the heart of argument evaluation. Everything else branches off from there. The second bumper-sticker slogan is:

Arguing well requires good arguers.

The return to an adjective, applying now to the arguers, signals that the admirable conduct of arguers ought to stem from virtues, inculcated habits of mind, rather than be accidental or occasional manifestations.

Why does this matter? Isn't an accidentally produced good argument just as good as a virtuously produced one? Even if we ignore the equivocation on both "good" and "argument" in this question, the answer is still "No" and for the same reasons that accidentally true beliefs do not count as knowledge. ${ }^{5}$ Otherwise, arguers would not have the requisite "ownership" of their

${ }^{5}$ Kvanvig , 2003, devotes several chapters to this question.

(C) Daniel H. Cohen. Informal Logic, Vol. 33, No. 4 (2013), pp. 471-485. 
arguments, a relation that grounds responsibility and the assignment of blame and credit.

And now, when we turn to asking what the virtues are that ground the role for virtues in argumentation, the earlier discussion comes back to bite us: having recognized so many different arguers, we have to acknowledge the possibility of different skill sets and different, possibly even incompatible virtues. Hilary Kornblith, in a delightfully provocative essay called "Distrusting Reason," gave voice to this idea:

Reason-giving requires a wide range of skills that need not be present in the reasons-responsive person.... [T]he ability to form one's beliefs in a way that is responsive to evidence is not at all the same as the ability to present reasons for one's beliefs. (Kornblith, 1999 p. 277)

The idea can be extended even further to spectators: When we think of someone who argues well as someone who marshals evidence, correctly draws inferences, and presents it well, we are putting them in the proponent's chair. Why not someone with whom it is good to argue, e.g., by listening well and asking the right questions, then accepts well-reasoned argumentation?

An opponent's ability to identify weaknesses in an argument are not always coincident with the ability to construct reasons in support of already adopted conclusions; neither must a judge necessarily have those proponent virtues; and openmindedness, sometimes cited as the arguer's virtue par excellence ${ }^{6}$ can actually be detrimental to the proponent's more partisan task (Cohen and Miller, 2008).

\section{Different arguers—and different arguments}

I said earlier that in order to extract meaning from the concept of a fully satisfying argument, we need to decide what counts as an argument, who counts as a participant, and what counts as satisfying. Starting with satisfaction, we were led to expand the concept of an arguer. Now, with the wide array of arguer-roles to consider, and each with its own skill-set and accompanying virtues, does the idea of an argument also have to grow a little? I think so, but not in ways that pose any significant problems for the virtues approach. If we think there are relevantly different kinds of arguments, Virtue Argumentation Theory can be easily adapted because it already accommodates a plurality of virtues. On the other hand, the plurality in Virtue Argumentation Theory

${ }^{6}$ Hare, 1985.

(C) Daniel H. Cohen. Informal Logic, Vol. 33, No. 4 (2013), pp. 471-485. 
is no obstacle to integration because even if we discern a single telos covering all kinds of argumentation, that need not translate into a single telos for all arguers.

And yet, in the end I would like to suggest that the common concept of an argument does need some expansion, not enlarge the range or extension of the concept, but rather to include its context.

\section{Conclusion: mise-en-scène}

Admittedly, many of the details are missing from this basic framework for thinking about completely satisfying arguments. Questions such as just which virtues are needed for the different roles in arguments, how they might relate to one another, how conflicts among them might be resolved, and how they differ from skills, have all been side-stepped here-mostly because all of them have been addressed at length by others elsewhere. What is missing and has not been addressed at length is precisely the context for an argument.

When it comes to satisfying arguments, the whole is greater than the sum of its parts, especially if the only parts we recognize as relevant are the arguers themselves. The venue matters. Evaluating an argument apart from its context is analogous to evaluating the inferential part of an argument, its illative core, apart from its dialectical tier: there are important things to be said about it, but there is more to the story. The wrong time or place can be as detrimental to the success of an argument as bad arguers. But so can the wrong arguers, not matter how good they are. And the same needs to be said about the subject matter, for if we lack the standing to effect the changes called for by the consensus that we reach, that too detracts from its satisfactoriness. So, unless we extend the concept of virtue to apply to contexts, and then talk about the "virtues of venues," virtue theory will not be enough. And that is inadvisable because it would require irreparable damage to the concept of a virtue as an inculcated habit of character.

Let me end, then, back where I began, with the virtues of OSSA.

It is no accident that there would be satisfying arguments here at this conference because it is the right place and the right time to argue, and we are the right people for arguing about the subjects of the arguments that will take place over the next few days. tradition

And besides, good arguments at OSSA? That's the (C) Daniel H. Cohen. Informal Logic, Vol. 33, No. 4 (2013), pp. 471-485. 


\section{References}

Aberdein, A. (2010). "Virtue in argument." Argumentation, 24: 165-179.

Aberdein, A. (2007). "Virtue argumentation." In F.H. van Eemeren, J.A. Blair, C.A. Willard \& B. Garssen (Eds.), Proceedings of the Sixth Conference of the International Society for the Study of Argumentation, pp. 15-19. Amsterdam: SICSAT.

Cohen, Daniel H. (forthcoming). "Skepticism and argumentative virtues." Cogency.

Cohen, Daniel H. (2008). "Now THAT was a good argument! On the virtues of arguments and the virtues of arguers." Santiago, Chile: Centro de Estudios de la Argumentación y el Razonamiento (CEAR).

The GoodWork Project: http://www.thegoodproject.org/goodwork/

Greco, John. (1999). “Agent reliabilism.” In James Tomberlin (Ed.), Philosophical Perspectives, 13, Epistemology, pp. 273-296. Atascadero, CA: Ridgeview Press, 1999.

Hare, William. (1985). In Defence of Open-Mindedness. Montreal: McGill-Queen's University Press.

Miller, G. \& D. Cohen. (2008). "Gods, gadflies, and bulldog tenacity: In defense of closed-mindedness." Conference on open-mindedness and the virtues in education. Halifax, Nova Scotia.

Kornblith, Hilary. (1999). "Distrusting reason." In P.A. French \& H.K. Wettstein (Eds.), Midwest Studies in Philosophy 23, pp. 181-196. Boston, MA: Blackwell.

Kvanvig, J. (2003). The Value of Knowledge and the Pursuit of Understanding. Cambridge: Cambridge University Press.

Sosa, Ernest. (1980). The Raft and the Pyramid: Coherence Versus Foundations in the Theory of Knowledge. Midwest Studies in Philosophy 5 (1): 3-26. Minneapolis, MN: University of Minnesota Press.

Zagzebski, Linda. (1996). Virtues of the Mind. Cambridge: Cambridge University Press. 